\title{
De la eco-historia a la ecología-mundo
}

\author{
From eco-history to world-ecology \\ Jean-Paul Deléage \\ Y DANIEL HÉMERY*
}

\section{RESUMEN}

Desde tiempos prehistóricos, las actividades humanas han transformado los ecosistemas. Pero es con la llegada del capitalismo industrial se ha traspasado un umbral histórico. A finales del siglo $X X$, la constitución de un espacio mundo productivo es el estandarte de la unificación ecológica del mundo: de la destrucción acelerada de especies, de la contaminación de los océanos, del agujero en la capa de ozono atmosférica amenazan hoy al planeta. En el Tercer Mundo, las tensiones ambientales son viejas conocidas, como la deforestación y la desertificación. Llevándolos al umbral de una economía-mundo, el capitalismo, tanto en sus versiones clásicas como en sus avatares "socialistas" ha empujado a las sociedades a una nueva relación con la naturaleza: la de un mundo ecológico.

\section{Abstract}

From prehistoric times human activity has transformed ecosystems. But it has been since the rise of industrial capitalism that a certain historical threshold has been reached. At the end of the Twentieth Century the creation of a world productive space implies the ecological unification of the world. The accelerated destruction of living species, pollution of the oceans, and the hole in the ozone layer threaten the planet Earth. These developments parallel previously existing environmental tensions such as deforestation and desertification. In creating a world economy, capitalism in its classical forms as well as in its « socialist » incarnations has projected societies into a new relation with nature, that of a world ecology.

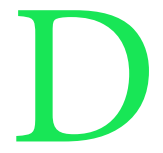

\section{e la ecohistoria al mundo ecológico}

Ya no es posible ignorar esta evidencia: el hombre no dispone con impunidad del planeta, no la domina, sino que es parte de él. Uno no puede ya no captar y comprender los determinantes ecológicos que modelan el futuro de las sociedades fuera de una reflexión profunda sobre el peso de los determinantes naturales en la larguísima duración de la historia. Sin embargo, esta reflexión histórica está todavía en pañales. Del mismo modo, el pensamiento ecológico suele ignorar los pocos datos disponibles sobre el pasado medioambiental de las grandes civilizaciones. Sin embargo, no es necesario demostrar el interés de una reflexión ecológica basada en un corpus sistemático de datos históricos debidamente analizados: es hoy una de las condiciones del dominio de nuestra propia historia.

\section{DOI:}

https://doi.org//0.15366/relacionesinternacionales2021.47.002

Formato de citación recomendado:

DELÉAGE, Jean-Paul y HÉMERY, Daniel (202I). “De la eco-historia a la ecología-mundo”, Relaciones Internacionales, $n^{\circ} 47$, pp. 53-66.

\section{* Jean-Paul DELÉAGE,} Físico, geopolitólogo e historiador de la ecología francesa, profesor honorario de la Universidad de Orleans..

\section{Daniel HÉMERY (1930-2019),} Historiador francés, especialista en la península de Indochina, profesor de la Universidad París VII-Diderot.

\section{Agradecemos} enormemente tanto a los autores como a la actual dirección de la revista "L'Homme et la société" por su generosidad a la hora de cedernos desinteresadamente los derechos para realizar esta traducción al castellano. Publicado originalmente en DELÉAGE, Jean-Paul y HÉMERY, Daniel (1989). "De l'écohistoire à l'écologiemonde", L'Homme et la société, $\mathrm{n}^{\circ}$ 91-92, pp. I3-30. DOI: https:// doi.org//0.3406/ homso. 1989.2386

Traducción: Rami ZAHRAWI HAJ-YOUNES 


\section{Temporalidades de la historia, temporalidades de la naturaleza}

Las sociedades y sus ecosistemas, todos los biotopos y entornos físicos en los que se integran y de los que extraen sus recursos, forman unidades vivas, interactivas y móviles. Por tanto, hay un tiempo ecológico en la historia, junto con tiempos económicos, culturales, políticos, etc. Cualquier abordaje de la ecología histórica debe por tanto interpretar las relaciones entre las poblaciones humanas y su entorno desde una perspectiva evolutiva, para considerar en diferentes escalas de tiempo el funcionamiento de los ecosistemas sociales, los mecanismos que aseguran su estabilidad y los procesos que, por el contrario, conducen a la degradación de sus fundamentos propiamente ecológicos.

La duración es, por tanto, una modalidad decisiva de las regulaciones ecológicas de la demografía humana. Si esta modalidad desaparece o cambia, y cesan las limitaciones o regulaciones. En cuanto a la estabilidad general de los ecosistemas humanos, es sólo aparente y la ecología histórica, que queda por establecer, tendría el interés específico de permitir identificar las principales perturbaciones que destruyen sus capacidades de estabilización. En el estado actual de nuestro conocimiento, lo que caracteriza la historia de las relaciones entre las sociedades y sus ecosistemas es la carrera permanente entre situaciones homeostáticas generando relativa estabilidad por la reproducción de estas relaciones y situaciones de ruptura que comprometen o, por el contrario, desarrollan la capacidad de las sociedades. para adaptarse a cambios definitivos en su entorno. De hecho, solo existen equilibrios socioecológicos dinámicos con un período más o menos largo.

Tres datos importantes caracterizan las temporalidades históricas del medio ambiente. En primer lugar, apenas existe una medida común entre su duración y la de la vida individual, la de las generaciones o incluso la de las grandes civilizaciones. El tiempo de los procesos biofísicos está más allá del alcance de la experiencia concreta de los hombres, ellos han conocido desde hace mucho tiempo y han utilizado solo las manifestaciones fenoménicas. Así, por ejemplo, hasta el desarrollo de los reactores nucleares, la producción social de energía consistía en captar una parte muy pequeña de los efectos energéticos de ciclos naturales muy complejos (ciclos de vegetación, ciclo del agua, etc. ciclo del viento, ciclos geológicos), para explotar de forma extremadamente fragmentada determinados eslabones o momentos del funcionamiento de cadenas energéticas muy largas. Pasó por el dominio de formas derivadas, fenómenos animales, plantas, minerales, etc. de energía solar. Lo que caracteriza a las duraciones ecológicas es tanto la infinitamente corta como la extremadamente larga, de ahí la impresión de una estabilidad muy fuerte que forma la base de la percepción que todas las generaciones han tenido hasta ahora de sus relaciones. En el medio que las rodeaba: "Una historia lenta Fluir, escribe Fernand Braudel, hecho muy a menudo de insistentes vueltas, de ciclos interminables reiniciados"'.

La noción de recursos, que se refiere a la disponibilidad de los ecosistemas con respecto a las necesidades sociales, su productividad social, tiene significación científica sólo si se considera en el muy largo plazo, de acuerdo con una escala de tiempo que supera con creces la extensión del tiempo. de la vida humana. Se estima que se necesitan cuatrocientos años para que la selva tropical climática primaria se regenere por completo en la zona tropical, que ahora se está reduciendo

Fernand Braudel, prefacio de El Mediterráneo y el mundo mediterráneo en tiempos de Felipe II, $2^{\mathrm{a}}$ edición, París, I 966, A. Colin, p. XIII y XIV. 
en un I\% de su superficie cada año. La capa de ozono que protege al planeta de la radiación ultravioleta y que se ve amenazada, en particular por la emisión de freones a la atmósfera, tardó unos dos mil millones de años en formarse bajo la acción de la actividad fotosintética de las plantas...

Segundo dato: los grandes ciclos físico-químicos tienen lugar según modalidades y limitaciones de tiempo extremadamente rígidas, que pesan mucho sobre el futuro de las sociedades. "El hombre", escribe Braudel, "está prisionero durante siglos en climas, vegetación, poblaciones animales, culturas, un equilibrio lentamente construido, del que no puede desviarse sin arriesgarse a ponerlo todo en tela de juicio"2. La restricción climática, muy estudiada por los geógrafos, es ahora bastante conocida en su funcionamiento histórico. Ha sido objeto de muchas investigaciones publicadas desde la década de 1950. Esta investigación muestra que existe una correlación muy fuerte entre la meteorología y la situación económica de las sociedades agrícolas como resultado de la sucesión de revoluciones agrícolas que comenzaron en el período neolítico. Emmanuel Leroy-Ladurie demostró que los seis años de lluvia continua desde I646 hasta I65 I fueron uno de los orígenes del profundo malestar económico y social que se expresó en la Fronda. Posteriormente, los calurosos años vegetativos I652-I687 se enfrentaron a las frescas primaveras y veranos del período 1687-I7I7, que hicieron escasear y encarecer la comida en las dos últimas décadas del Grand Siècle. Más recientemente, el trabajo de Christian Pfister, de la Universidad de Berna, ha demostrado la importancia de las variaciones climáticas en el precio de los cereales y, más en general, en los ciclos económicos en las sociedades preindustriales y más allá, en la Europa continental. construcción de redes ferroviarias ${ }^{3}$.

Ahora se conocen una serie de grandes fluctuaciones climáticas, vinculadas a cambios en el flujo zonal de oeste a este de las masas de aire en la atmósfera inferior. Las fases de óptimo y pessimum no han dejado de seguirse en una Europa donde el tiempo está marcado por ciclos naturales: gran óptimo caliente del fin de la prehistoria (de 5000 a 2300) que habría favorecido los primeros claros; prolongado deterioro subadantico del período antiguo y comienzos del primer milenio de nuestra era que parece haber ido acompañado de una renovación de la vegetación y los bosques naturales; breve tibio óptimo del año 1000 (lx* al $\mathrm{xn} *$ siglo) que coincide con el establecimiento de áreas rurales en Europa Occidental;"Pequeña edad de hielo" de 1590 a I750; calentamiento del siglo XVIII-XIX seguido de la secuencia húmeda del siglo XX.

Asimismo, en otra área geohistórica, hemos podido correlacionar el declive a partir del siglo XIII de la agricultura indígena de regadío en el suroeste de los actuales Estados Unidos, con la desertificación de inmensas regiones de las cuencas de Colorado, del Gila, del Río Grande, con la larga sequía de la segunda mitad del siglo XIII; esto iba a causar un declive demográfico prolongado que el campesinado indio nunca pudo superar.

Tercer dato: nunca hay reversibilidad absoluta en la escala temporal de la naturaleza. Como hemos visto, la dinámica de la producción humana puede alterarse profundamente, a

\footnotetext{
Fernand Braudel,“La larga duración”, Annales E.S.C., oct.-déc. 1958.

Véase en particular Emmanuel Leroy-Ladurie, Historia del clima desde el año mil, París, 1967, Flammarion y El territorio del historiador, París, 1973, Gallimard, tercera parte; Jacques Labeyrie, El hombre y el clima, París, I985, Denoel; Pfister, “Fluctuaciones climáticas y precios de los cereales en Europa del siglo XVI al XX”, Annales E.S.C., I988, I, págs. 25-53.
} 
veces inmediatamente, a veces después de un retraso. Sin embargo, ejerce una retroalimentación sobre los ecosistemas porque se combina con los factores físicos endógenos de degradación, entropización de estos ecosistemas, pesando hasta el punto de hacer irreversibles sus efectos. Cuando las temporalidades de la historia humana se anteponen a las temporalidades de la historia ecológica, los umbrales se traspasan definitivamente en la no reproducción de los ecosistemas o hacia su creciente entropía. La humanización de la naturaleza no le da al mundo salvaje una oportunidad dos veces.

Pero el traspaso de los umbrales de irreversibilidad bajo el efecto de causas entrópicas solo se logra al final de procesos lentos. La historia de los ecosistemas presenta profundas discontinuidades entre los períodos de acumulación de elementos, de su desequilibrio y los momentos de ruptura repentina y puntual de su estructura constitutiva. Los primeros preparan al segundo, pero los segundos son más fáciles de detectar porque resultan en desastres ecológicos con efectos devastadores: inundaciones cataclísmicas, roturas de diques fluviales, sequías prolongadas en zonas desertificadas, etc.Así, hoy la atmósfera media terrestre es el asiento de un fenómeno de acumulación de este tipo. Fue producido por la actividad fotosintética de los seres vivos y tomó varios.

mil millones de años para que se forme. Pero desde hace poco más de dos siglos, el uso creciente de combustibles fósiles, diez mil millones de toneladas equivalentes de carbón, de todas las fuentes, en 1987 ha acumulado gradualmente en sus capas inferior y media una cantidad creciente de contaminantes atmosféricos, en particular C02, cuya concentración en el aire aumenta a un ritmo de, etc. 4 I,3 ppm / año, SO2, liberado a un ritmo de II0 millones de toneladas por año, etc 4 .

\section{Un conflicto social, universal y multimilenial con la naturaleza}

Las determinaciones ecológicas atraviesan todo el campo social y no se limitan a determinadas áreas particulares de este campo. Es solo a través de la aparición de nuevos sistemas de exploración de la naturaleza, de nuevas formas de producción agrícola e industrial que las formas de explotación social, los procesos de apropiación desigual de los medios de producción, de la tierra, la ganadería, el agua, los recursos subterráneos. “En todas partes”, escribe Maurice Godelier, "aparece un vínculo íntimo entre la forma de utilizar la naturaleza y la forma de utilizar al hombre" 5 . En cualquier sociedad, es en la apropiación de la naturaleza donde los hombres cooperan o se explotan, donde se organizan y transforman sus relaciones de producción y sus relaciones sociales. "No hay crisis en el uso de la naturaleza que no sea una crisis en la forma de vida del hombre"6.

Desde tiempos prehistóricos, las actividades de depredación y producción humanas han llevado a la reducción general y la transformación continua de los ecosistemas naturales

\footnotetext{
4 François Ramade, Ecological catastrophes, París, 1987, McGraw-Hill, p. I83- I84; particularmente significativos en este sentido en términos de sus posibles efectos globales son el aumento de la tasa de dióxido de carbono o la disminución de la de ozono en la atmósfera; véase John R. Trabalka y Dieter E. Reichle, The Changing Carbon Cycle. Un análisis global, Springer Verlag, I 986 y Tellus, 39 B, I 986.

5 Maurice Godelier, El ideal y el material. Pensamiento, economías, sociedades, París, I 984, Fayard, p. I 55.

6 P. Gourou, Lecciones de geografía tropical, París, I97I.
} 
o seminaturales, de acuerdo con una serie de tendencias importantes durante varios siglos, e incluso durante varios milenios. Por lo tanto, las tensiones ecológicas actuales tienen un origen muy remoto, son el resultado de crisis ambientales acumulativas. Ninguna civilización ha sido ecológicamente inocente. Mucho antes de la industrialización europea de los tiempos modernos, la actividad humana demostró ser profundamente destructiva del tejido ecológico y la sometió a cambios irreparables, el más antiguo y generalizado de los cuales fue la deforestación. Esto fue al revés y condición para el desarrollo de la caza y la recolección, la agricultura, la ganadería, la artesanía y las actividades protoindustriales. De hecho, en todo el mundo, los ecosistemas naturales desorganizados han sido reemplazados por agrosistemas que incorporan, por supuesto, muchas especies naturales que se han convertido en las piedras angulares de todos los complejos ecológicos actuales. Su formación y luego su generalización habrán resultado en última instancia en la destrucción irreversible de los equilibrios naturales primarios y su sustitución por equilibrios secundarios inestables. Es en el bosque donde las sociedades preindustriales han depositado la mayor parte de su cosecha destructiva.

Se puede comprender muy pronto en China, donde la falta de nuevas tierras va acompañada en muchas ocasiones de desequilibrios ecológicos y escaseces físicas creciente. La deforestación está devastando muchas regiones, un efecto directo o indirecto de la continua expansión del sistema de cereales. J. Needham notó su seriedad ya en el siglo XVI en las tierras altas de Shaanxi y Gansu' ${ }^{7}$. Durante un tiempo comprobado por la enérgica política de reforestación implementada alrededor de 1580 en estas provincias, se dice que se reanudó a fines del siglo XVIII y, por lo tanto, está progresando rápidamente en las regiones al norte del Yangtze. De hecho, la destrucción del bosque en los valles altos es antigua. En la cuenca del río Amarillo, sin duda, se remonta a los primeros siglos del Imperio. Quizás fue también una de las razones del lento deslizamiento de la civilización china del noroeste al sureste entre el período Tang y el de Song. El imperio Song habría basado entonces su brillante desarrollo urbano y naval en la explotación de reservas de madera en las cadenas montañosas del sur y en las importaciones de madera japonesa. Para los tiempos modernos, S. Ashead ha planteado la hipótesis de la apertura en China de una crisis energética prolongada entre 1400 y $1800^{\circ}$. En el mundo musulmán, la obra de Maurice Lombard ha mostrado la aparición de una escasez de madera desde el siglo XVII tras el aumento de la demanda resultante del brillante desarrollo urbano en la tierra del islam. Debemos ir cada vez más lejos, en el lado cristiano del Mediterráneo, en busca de combustible, cuyo costo está aumentando. Desde principios del siglo XI, "Frente a un Occidente todavía asfixiado por los bosques, pero que empezó a utilizarlos para sus barcos, para sus construcciones, para sus industrias, el mundo musulmán fue decayendo y cediendo"'.

Esta crisis también afecta a Europa, pero en mucha menor medida. En el Atlántico y Europa Central, la limpieza progresó desde el comienzo de la Alta Edad Media. En Germania, el bosque herciniano tenía, según los autores romanos, una longitud equivalente a sesenta días de caminata. Retrocede rápidamente a partir del siglo VI. El bosque primario templado se está degradando hacia un bosque controlado y humanizado, bajo el efecto del cultivo del espacio y la demanda de

\footnotetext{
J. Needham, Ciencia y civilización en China, IV, Física y tecnología física, 3, p. 240 pies cuadrados.

8 S.A.Adshead, “Una crisis energética en la China moderna”, Ch’ing-shih Wen-t’i, vol. m, diciembre de 1974.

9 Maurice Lombard, “Un problema cartográfico: la madera en el Mediterráneo musulmán (siglos VII-XII)” y “Arsenales y madera marina en el Mediterráneo musulmán (siglos vn * - xr *)” en M. Lombard, Espaces et Réseaux du High Middle Ages, París La Haye, 1972 , Mouton.
} 
combustible y madera. El apogeo del gran claro se produjo entre mediados del siglo XI y finales del siglo XIII. En el siglo XIV, los ecosistemas europeos alcanzaron el punto de saturación, Europa Occidental era verdaderamente un mundo lleno. Ha llegado el momento de las grandes crisis ecológicas que presagian lo que se ha dado en llamar la "revolución industrial", una revolución que se extiende a lo largo de varios siglos.

A partir del siglo XVI, de hecho, en Inglaterra, y sin duda también en los Países Bajos, se inició una grave y prolongada crisis de la madera, que se extendió luego al continente ${ }^{10}$. Si la primera sustitución masiva de combustibles fósiles por combustibles vegetales y la revolución energética de los tiempos modernos tuvieron lugar primero en Inglaterra, es porque la madera se iba a acabar primero. La escasez de madera marca dramáticamente la era isabelina y la de los Estuardo desde 1550 hasta 1700, aunque la deforestación antropogénica muy temprano destruyó los bosques del norte de la isla, en particular el inmenso bosque de pinos de Caledonia que cubría las tierras altas de Escocia en el comienzo de nuestra era. Es causado por el crecimiento de la población, la población de Inglaterra y Gales casi se duplicó entre 1530 y 1690 (de tres a casi seis millones de habitantes), amplificada por el aumento de la demanda de las ciudades en plena expansión. Bajo Isabel I “(I558-I603) y bajo Jacques ler (I603-1625) la subida del precio de la madera fue vertiginosa y superó en ritmo al de otros productos. En 1776, en su Investigación sobre la naturaleza y las causas de la riqueza de las naciones,Adam Smith escribe que, en Edimburgo, su ciudad natal, "probablemente no había ni una sola pieza de madera escocesa" ... Esta crisis de la madera no es solo inglesa. Un poco como China en Al mismo tiempo, todo Occidente La civilización entró en una situación de inestabilidad ambiental recurrente entre los siglos XVI y XVIII, en un proceso de creciente distorsión entre su demanda amplificada de medios de subsistencia generada por su crecimiento a lo largo de los años. Considerados tres siglos y las posibilidades del medio ambiente, surge contra un límite ecológico del cual las limitaciones de la deforestación son el elemento central.

\section{Crisis ecológicas y crisis sociales}

La historia, en su estado actual, aún no es capaz de establecer correlaciones precisas entre las limitaciones ecológicas y el destino de las civilizaciones pasadas, con la posible excepción de las consecuencias que han tenido sobre este destino: grandes desastres naturales, que no pueden considerarse despreciables. Las fluctuaciones climáticas han pesado mucho sobre las crisis sociopolíticas de las sociedades agrarias. Así, en Francia, los veranos muy calurosos de los cuatro años I778-I78I, óptimos para la producción de cereales y vinos, son uno de los principales factores de la célebre crisis de los precios agrícolas, estudiada por Ernest Labrousse, que se prepara para 1789. Por el contrario, el calor y la sequía del verano de 1788 provocaron escaldaduras en las orejas, cuyos efectos se vieron amplificados por el famoso granizo gigante del 13 de julio, en el norte de la Cuenca de París. Las catastróficas cosechas que siguieron provocaron el alto precio del grano, que alimentaría la angustia campesina del Gran Miedo a principios del verano de 1789;

\footnotetext{
10 Lucien Febvre, La tierra y la evolución humana, Introducción geográfica a la historia, París, I922, La evolución de la humanidad, p. I58. Roger Dion, “Fábricas y bosques. Consecuencias del antiguo uso de la madera como combustible industrial”, Revue des Eaux et Forêts, octubre de 1938, p. 77I-782; Louis Trénard, “El carbón antes de la era industrial”, m El carbón y las ciencias humanas, Actas del Coloquio organizado por la Facultad de Letras de la Universidad de Lille en mayo de 1963, París-La Haye, 1966, Mouton; John U. Nef, “Las consecuencias históricas de una crisis energética histórica", Pour la Science, febrero de 1978.
} 
ansiedad agravada por la degradación del suelo en muchas partes de Europa ".

En cuanto a las grandes crisis del bosque y la ecosfera, ijugaron un papel en el colapso de las civilizaciones antiguas o en su declive? Esta hipótesis se planteó para explicar la repentina caída a principios del siglo $X$ de la civilización maya del actual departamento de Petén en Guatemala y Honduras: la degradación del ecosistema forestal y el ciclo del agua habría arruinado la agricultura maya basada en el sistema "miipa" (cultivo de maíz de roza y quema con barbecho de cuatro a ocho años). Pero esta hipótesis no se pudo verificar ${ }^{12}$. Por otro lado, es cierto que la desorganización de la hidrología jugó un papel importante en el debilitamiento de las civilizaciones mesopotámicas, en particular la erosión del suelo tras la deforestación y el pastoreo excesivo de las cuencas altas del Tigris y el Éufrates. La deforestación acelerada, bajo el efecto de la necesidad de leña y construcción, el desmonte para la creación de pastos para los rebaños, la extensión de la arboricultura en las laderas, provocaron una creciente sobrecarga aluvial de los dos ríos. Los imperios de Babilonia y Siria no lograron evitar la obstrucción de la gigantesca red de irrigación de la Baja Mesopotamia, por lo que la civilización del creciente fértil entró en un lento proceso de declive que fue coronado por la destrucción de los canales de irrigación en el siglo $X$ por los invasores mongoles ${ }^{13}$. Durante los últimos tres milenios, el delta común de los dos ríos ha ganado más de $250 \mathrm{~km}$ del mar bajo el efecto de depósitos aluviales. También se ha propuesto una explicación del mismo tipo por la sedimentación del sistema baray (reservorios artificiales) y la saturación del espacio cultivable para dar cuenta del colapso del imperio angkoriano ${ }^{14}$. En la zona mediterránea, es también desde la más alta Antigüedad que se han alterado los equilibrios naturales primarios, la deforestación ha afectado a vastas regiones desde la época romana. En el mundo musulmán, la escasez de madera también ha representado una amenaza formidable desde el siglo I en adelante. No hubo nada dramático mientras los estados musulmanes del Mashreq y el Magreb tuvieran un suministro regular de oro sudanés, lo que les permitió pagar ventajosamente sus compras de madera. Pero con la llegada de los árabes de Hilalia, las rutas del oro transaharianas, cuyo control aseguraba la prosperidad del Egipto fatimí, se cortaron y todo el Oriente musulmán se debilitó ${ }^{15}$.

En última instancia, la conclusión a la que llegan los escasos estudios históricos disponibles es que la degradación del medio ambiente, antiguo en muchas áreas geográficas, solo ha jugado un papel en la interferencia con otros factores sociales (económicos, técnicos, culturales, etc.) y más como límite global que como causa inmediata y directa. A través de la mediación de estos factores, cualquier crisis ambiental grave resulta en un declive retardado, temporal o duradero de la civilización que la provocó, un declive que lleva a su colapso o a la mutación de sus estructuras subyacentes. Pero este declive generalmente solo se produce durante períodos muy prolongados y solo si la sociedad no está en condiciones de desarrollar mecanismos compensatorios para la crisis ecológica, como el desarrollo de intercambios a distancia, o de inventar los medios técnicos y económicos de crecimiento diferente ${ }^{16}$.

\footnotetext{
"P. Blaikie y H. Brookfield, Land Degradation and Society, Methuen, 1987; para Francia, véanse en particular las numerosas obras de J.Vogt.

12 J.E.S.Thompson, El ascenso y la caída de la civilización maya, París 1973, Payot.

13 F. Ramade, op. cit., pág. 127

14 B.P. Groslier, “Agriculture and religion in the Angkorian Empire”, Estudios rurales, enero-diciembre de 1976.

15 Maurice Lombard, op. cit.

16 K. Pomian, “Los límites ecológicos de las civilizaciones”, Social Science Information, 1976, XV, I; L. White, “Las raíces históricas de nuestra
} 
En la mayoría de los casos históricos enumerados, el peso de las representaciones que desarrollan las sociedades sobre su relación con el medio parece haber jugado un papel importante, pues es a partir de estas representaciones que actúan sobre este último. Estas representaciones favorecen o por el contrario ejercen un efecto limitante sobre las grandes y devastadoras retiradas. En términos generales, hasta la industrialización masiva de Europa entre los siglos XVI y XIX, la relación con la ecosfera se pensaba como un "intercambio" con fuerzas naturales, a menudo sagradas en cierto número de mitos o cosmologías religiosas, y no como un "transformación de la Naturaleza", y menos aún como transformación de la "naturaleza" de los hombres, considerándose esta última como un componente de la naturaleza cósmica. Por supuesto, en este tipo de visión, la naturaleza no se percibe bajo sus únicos aspectos sensibles sino como un conjunto de fuerzas y poderes invisibles que controlan el futuro del grupo humano. "Todas las formas de actividades concretas que el hombre ha inventado para adecuarse a las realidades naturales", escribe Maurice Godelier, "contienen y combinan al mismo tiempo y necesariamente gestos y comportamientos" materiales "para actuar sobre sus aspectos visibles y tangibles. comportamientos que hoy llamamos "simbólicos" para actuar sobre su fondo invisible" |7. En este tipo de cultura, donde el hombre es la principal fuerza productiva, la adaptación al ecosistema es el principio fundamental del funcionamiento de la sociedad, pero este principio opera según un abanico muy amplio de modalidades concretas. En este sentido, el desarrollo de los sistemas agrícolas en el período neolítico representó ciertamente un importante umbral histórico, al abrir la posibilidad de una diferenciación de formas de pensar sobre la relación entre el hombre y la naturaleza.André Haudricourt ha demostrado que "frente al mundo vegetal y animal del Neolítico, el hombre ya no es solo un depredador y un consumidor, en adelante asiste (subrayado por el autor), protege (ibidem), convive durante mucho tiempo con la especie que ha "domesticado". Se han establecido nuevas relaciones de tipo "amistoso" que recuerdan a las que los hombres mantienen entre sí dentro del grupo" ${ }^{18}$.

En consecuencia, varios modelos de tratamiento de la naturaleza se separan. Como muestra A. Haudricourt, los métodos de acción indirecta sobre plantas desarrollados en el contexto de los campos de arroz o la horticultura de tubérculos de los melanesios se oponen a la acción más directa y dominante de los agricultores occidentales. "No hay amistad posible, enseña Aristóteles, hacia las cosas inanimadas, como tampoco la hay entre el hombre con el caballo y el buey o incluso entre el amo y el esclavo como esclavo. De hecho, en todas las sociedades antiguas que han conocido la agricultura, un inmenso conocimiento empírico y enciclopédico se constituye en la naturaleza, que dio lugar a la construcción de los primeros grandes sistemas intelectuales. Hoy podemos ver las relaciones causales entre los grandes sectores ecológicos y estos grandes sistemas de representación de la naturaleza. Pero las situaciones ambientales reales siguen siendo opacas. Su comprensión solo se establece en los planos de la cosmología, la metafísica o la teología. En estas condiciones, difícilmente podemos atribuir a estas culturas una estrategia ambiental global.

\footnotetext{
crisis ecológica", Science, No. 155, 1967.

17 Maurice Godelier, op. att., pág. 66.

18 André Haudricourt, “Domesticación de animales, cultivo de plantas y tratamiento de otros”, L'Homme, París, U, I, enero-marzo de 1962.
} 


\section{El advenimiento del capitalismo industrial y el gran avance ecológico}

El advenimiento del siglo ha operado y la expansión de una verdadera revolución del capitalismo en la representación industrial desde el colectivo de la Naturaleza. La idea de la solidaridad Hombre / Universo físico ha sido reemplazada por la del dominio de la Naturaleza por el Hombre. Es desde el siglo XVI cuando la visión prometeica de la sumisión de la naturaleza a los humanos se ha vuelto hegemónica en la cultura occidental. Entre 1500 y I800, el precepto del Génesis $(I, 28)$ "Llena la tierra y sométela" se convirtió, bajo la influencia acumulativa de la Reforma y la Contrarreforma, como bajo la del cientificismo de los siglos xvm- xixc, uno de los axiomas fundacionales de esta cultura, y con él se arraiga el antropocentrismo absoluto. "El hombre, si buscamos causas finales, puede ser considerado el centro del mundo”, proclamó Francis Bacon en el siglo XVI. “Debemos hacer garganta a la naturaleza", escribió Isaac Newton dos siglos después ... El hombre ahora tiene autoridad absoluta sobre la ecosfera, la naturaleza es ciertamente objeto de celebración, pero solo como un espacio de ocio, de ensueño, nostalgia, espacio humanizado ${ }^{19}$. Evocando "la gran acción civilizadora del Capital", Marx expresará en términos positivos la devaluación cultural e ideológica de la naturaleza que en todas partes ha legitimado los procesos de industrialización durante tres siglos: "U [El Capital] se eleva a tal nivel social. las sociedades aparecen como desarrollos puramente locales de la humanidad y como una idolatría de la naturaleza ... la naturaleza se vuelve un objeto para el hombre, una cosa útil"20.

Esta transformación en las representaciones de la relación de las sociedades con el mundo, obviamente, no es separable de la transformación de esta relación en su misma materialidad. $\mathrm{Y}$, ante todo, el recurso a sustituciones masivas de materias primas y combustibles, fósiles en particular, que darán a las empresas industriales que afrontan graves problemas medioambientales un margen de maniobra sin precedentes.

Esta historia es muy conocida, pero quizás convenga recordar muy esquemáticamente lo esencial $^{2 !}$.

La crisis de la madera en Inglaterra se mitigó primero con la reforestación y las importaciones masivas de madera escandinava y norteamericana, y luego se resolvió con la reducción masiva de existencias del enorme depósito de combustibles fósiles que ocultaba el subsuelo británico.A partir de mediados del siglo XVII, el uso del carbón se generalizó, gracias a la posibilidad de transportarlo por mar desde Newcastle a Londres, luego en el siglo XVIII, gracias a la construcción de una red de canales que permitió 'Bajar drásticamente los costos del carbón en el interior del país. En la época de la Guerra Civil, hacia 1640, a pesar del humo nauseabundo que emitía, el carbón traído en barco el "seacoal" se convirtió en imprescindible para el calentamiento de los londinenses. La intensidad del cabotaje de carbón se multiplicó por veinte entre I550 y 1700, las importaciones de combustible de Londres se multiplicaron por treinta y alrededor de

19 Keith Thomas, En el jardín de la naturaleza. La mutación de sensibilidades en Inglaterra en la era moderna (I500- I 800), París, I985, Gallimard; en este punto, también hemos insistido a menudo en la relación entre la dominación sobre la naturaleza y la dominación masculina sobre el sexo femenino; véase en particular Carolyn Merchant, La muerte de la naturaleza, las mujeres, la ecología y la revolución científica, Nueva York, Harper and Row, 1983

20 Karl Marx, fundamentos de la crítica de la economía política, I857-1858, París, 1967, Anthropos, I. I, p. 367.

${ }^{21}$ Sobre este punto, véase en particular nuestro trabajo: J.C. Debeir, J.P. Deleage, D. Hemery, Las servidumbres del poder, una historia de la energía, París, 1986, Flammarion. Para los problemas de contaminación resultantes, el notable trabajo de Peter Brimblecombe, The Big Smoke, Methuen, 1987 
I700, el Reino Unido produjo al menos tres millones de toneladas de carbón cada año. La era de los combustibles fósiles, que revolucionará el mundo, está en marcha y, al mismo tiempo, la de la contaminación industrial a gran escala.

En Francia, el problema de los costes de transporte se resolverá en el siglo XIX con el equipamiento ferroviario del país. La movilización de conocimientos científicos y técnicos está, por tanto, en gran medida en el origen del fenómeno de la sustitución, que permitió superar la crisis forestal. Esta sustitución generó en Inglaterra, a partir del siglo XVII, un extraordinario avance técnico en la mayoría de las áreas de producción industrial: uso del carbón para la fabricación de vidrio a partir de 1610, invención del horno reverberatorio para fundir metales no ferrosos hacia 1660, hornos de ladrillos funcionando con carbón, invención del proceso Darby para la fundición de coque en 1709, charcos en 1784 y, finalmente, el desarrollo de un revolucionario convertidor de energía con las máquinas de vapor de Newcomen (I7I2) y de Watt (I784)... En cierto sentido, la gran industria nació de las tensiones ecológicas. Pero la respuesta opuesta a esta última ha traído nuevas formas de degradación ambiental y un tremendo cambio en el tiempo y el espacio en las tensiones ecológicas.

No es exagerado decir que con el advenimiento del capitalismo industrial se ha traspasado un umbral histórico en la degradación de los ecosistemas. Con la industrialización masiva, la contaminación y la degradación ambiental tienden a generalizarse; se convierten en un hecho real de la civilización y adquieren, en el siglo XX, más particularmente desde la Segunda Guerra Mundial, dimensiones planetarias.

\section{Hacia un mundo ecológico}

A finales del siglo $X X$, la constitución de un espacio productivo global es portadora de la unificación ecológica del mundo. En primer lugar, triunfa la tendencia a la artificialización de los ecosistemas vegetales. El bosque, la hierba, ahora se cultivan, las especies de plantas seleccionadas y estandarizadas, la selva alta está "ajardinada”. La artificialización se está extendiendo a la fauna acuática en agua dulce antes de extenderse a la fauna marina. Los agrosistemas artificiales toman el lugar de la "naturaleza". Todos se caracterizan por sus considerables necesidades energéticas y su fragilidad. Uno de los factores potencialmente más peligrosos en la modificación de los ecosistemas está relacionado con la mejora de las plantas, que depende de un suministro constante de variabilidad genética. Hasta la Segunda Guerra Mundial, estas contribuciones provenían principalmente de centros de variabilidad ubicados en países del Tercer Mundo. Sin embargo, es en este último donde, dado que se han establecido la mayoría de los centros de mejora, las nuevas variedades de alto rendimiento reemplazan a las antiguas poblaciones locales diversificadas.

Para muchas plantas cultivadas, cereales en particular, se ha superado el punto de no retorno. De hecho, el crecimiento de la población es tal que el uso masivo de nuevas variedades de alto rendimiento es irreversible si ahora queremos evitar la escasez crónica de alimentos. Esta situación conlleva enormes riesgos ecológicos. "I) Las diversas poblaciones que se reemplazan pueden perderse para siempre si no se recolectan y mantienen a tiempo; 2) la sustitución de material genético uniforme por poblaciones locales mixtas y adaptadas es una invitación a 
epidemias desastrosas de diversas enfermedades y parásitos” escribe J.R. Harlan²2.

En los "nuevos países", el bosque fue destruido desde el siglo XIX por el desmonte o para el suministro de combustible a un ritmo sin precedentes. En los Estados Unidos, sólo quedan hoy diez millones de hectáreas de los ciento setenta millones que cubrían el inmenso bosque primitivo de árboles de hoja caduca entre el Atlántico y el Mississippi. En Canadá, el bosque de coníferas es solo un tercio de lo que era antes de la llegada de los europeos. La limpieza, inadecuada para los suelos del centro oeste de América del Norte, desencadenó ciclos de erosión eólica y creó las condiciones para la formación de "tazones de polvo". A finales del siglo XX, la deforestación es tal que supera con creces la tasa de renovación de los recursos forestales globales del planeta. En el bosque de Siberia, la tasa de tala supera en un $150 \%$ el crecimiento anual medio de los denominados bosques de producción. Desde principios de la década de 1980, la destrucción neta de la selva tropical ha progresado, según la FAO, a un ritmo de I5,7 millones de hectáreas por año, el equivalente a la selva francesa, la mayor de Europa ${ }^{23}$.

Desde mediados del siglo $X X$, vemos un aumento continuo en la frecuencia de desastres ecológicos de origen antropogénico" 24 , en correlación con la precipitada carrera hacia una innovación técnica descontrolada: la enfermedad de Minamata en la década de 1950, efectos a largo plazo. diseminación en la biosfera de insecticidas como ddt y plastificantes, derrames repetidos de petróleo (Amoco Cádiz en marzo de 1978, incendio del pozo submarino Nowruz en el Golfo Pérsico en 1983), etc.

En particular, la contaminación de la biosfera y la atmósfera está adquiriendo proporciones catastróficas. Hasta mediados del siglo XX permaneció ubicado en núcleos industriales donde, a partir del siglo XVII, se desarrolló entre la población trabajadora un raquitismo, que parece desconocido para los pueblos prehistóricos y que se debe a la carencia de rayos ultravioleta. Se menciona por primera vez en Inglaterra en 1650, y un mapa del azote elaborado en I889 muestra que sus principales focos son Aberdeen, Dundee, Glasgow, Edimburgo, Newcastle, Manchester, Liverpool, Birmingham, Cardiff y Londres. En los países industrializados, la contaminación por dióxido de azufre es antigua, pero estaba confinada al entorno inmediato de los emisores. Uno de los casos más conocidos es el de la planta metalúrgica de Sudbury en Ontario: encargada en 1888 , destruyó las 200.000 hectáreas de pinar que la rodeaban. A partir de la década de 1950, el sistema industrial funcionó como un vulcanismo artificial real en un estado de actividad no solo permanente sino también creciente. Dos tipos de contaminantes ejercerán una acción particularmente destructiva en la escala de toda la biosfera.

En primer lugar, las colosales cantidades de emisiones gaseosas resultantes de la combustión de diversas formas de carbono fósil (hulla, lignito, petróleo, gas). Se trata de los derivados gaseosos del carbono: el dióxido de carbono (CÔ2), principal contaminante en volumen, emitido por estas combustiones a razón de 25.000 millones de toneladas anuales a la atmósfera

22 John iR. Harlan, Plantas cultivadas y hombre, París, I 987, P.U.F. Sobre los costos de la energía de la agricultura contemporánea, véase, por ejemplo, D. Pimentel, Handbook of energy utilization in Agriculture, CRC Press, Florida, 1980.

23 Ramade, op. cit., págs. I9I-I93. E. Georges, “Los gigantes con pies de arcilla”, Geo, septiembre de I 986; J. Boulbet, Forêts et pays, Publicaciones de la Escuela Francesa del Lejano Oriente, París, 1984.

24 F. Ramade, op. cit., pág. 4.Ver también: L.A. Chambers, “Air pollution in historical perspectiva”, en Robert Detweiler, John N. Sutherland, M. S. Werthmann, Environment decay in its historical context, Glenview, Illinois, 1973. 
en los años 80 , responsable del incesante aumento de su concentración. en el aire, susceptible de provocar un calentamiento artificial del clima de la Tierra en el siglo XXI; monóxido de carbono, liberado a razón de 350 millones de toneladas por año; hidrocarburos no quemados; Óxido de nitrógeno, dióxido de azufre (SO2) y anhídrido sulfúrico (SO3), emitidos a razón de 100 millones de toneladas por año, particularmente implicados en la lluvia ácida. La acción de los microcontaminantes atmosféricos producidos por innumerables reacciones no es menos dañina, peroxi-acil-nitratos, partículas ..., la contaminación atmosférica se ha ido globalizando poco a poco, como lo demuestra el aumento de partículas sólidas en las últimas capas de la capa de hielo antártica, pero muy lejos de fuentes contaminantes. A esta lista ya larga, hay que añadir la difusión mundial de la radiactividad tras los ensayos nucleares militares o los accidentes en instalaciones nucleares civiles, de los que Chernobyl se ha convertido en un símbolo preocupante. Una de las consecuencias más dramáticas es el fenómeno de la lluvia ácida.

Hasta la Revolución Industrial, el agua de lluvia era prácticamente neutra en un entorno continental. El pH del agua de deshielo obtenido al extraer muestras de la banquisa de Groenlandia estaba entre 6 y 7,6 antes de 1800 . Fue exactamente entre 1950 y 1979 que el $O$ aumentó bruscamente en los lagos suecos, mientras que se había mantenido notablemente estable durante los últimos 12.500 años desde la Glaciación de Würm. Los estudios realizados desde $1960^{25}$ han demostrado que el $\mathrm{pH}$ medio de las precipitaciones se ha reducido drásticamente en el centro y norte de Europa (ahora el pH es inferior a 5). En los Estados Unidos, cayó de 5.9 en 1939 a 4.2 hoy en verano ${ }^{26}$. De hecho, la acidificación de las lluvias afecta a todo el hemisferio boreal y la curva iso-pH5 alcanzada desde 1980 en Singapur. Desastre ambiental sin precedentes, con la muerte ecológica de cientos de lagos y ríos en Europa y América del Norte por la desaparición de biocenosis acuáticas y con la degeneración de inmensas áreas forestales, que ahora incluyen algunas grandes selvas tropicales en China y Brasil. Pero es en el Tercer Mundo donde en el siglo $\mathrm{XX}$ la crisis ecológica adquiere sus aspectos más alarmantes porque se concentran los fenómenos de ruptura ambiental de la era preindustrial y los de la era industrial en conjunción con la expansión de la era industrial. "dúo superpoblación / subdesarrollo" ${ }^{27}$ y con la industrialización en curso. La presa de Asuán es una prueba ejemplar de ello: al retener los sedimentos del Nilo, puso fin a las famosas crecidas del río y arruinó la pesca en el mar en las desembocaduras del delta.

En cuanto a las crisis ambientales de origen industrial, tal vez sean peores hoy en los países del Tercer Mundo que en el pasado en las sociedades anteriormente industrializadas. Realidad simbolizada en 1983 por la situación de la ultramoderna fábrica de Bhopal, rodeada de un enorme barrio pobre poblado por miserables campesinos. Además, si en el Tercer Mundo no ha aumentado la frecuencia de los desastres naturales, sus efectos humanos no han dejado de agravarse como consecuencia de la explosión demográfica que empuja al campesinado sin tierra a migrar a las zonas de alto riesgo, especialmente en las fértiles tierras volcánicas. tierras. El impresionante crecimiento de la degradación ambiental es, además, un factor cada vez más activo en los desastres naturales. La destrucción de áreas boscosas en las cuencas hidrográficas aumenta la frecuencia de las inundaciones. Esta correlación se puede ver en todas partes del Tercer Mundo.

\footnotetext{
${ }^{25}$ F. Ramade, op. cit.

26 Ibid., pág. 193.

27 Ibídem, pag. 4. Esta crisis es particularmente grave en África; véase Loyd Timberlake, África, en Crisis: las causas, las curas de la quiebra medioambiental, Earthscan en rústica, Londres, 1985. 28. F. Ramade, op. cit., pág. 15.
} 
Así, en el subcontinente indio, la deforestación de las laderas bajas del Himalaya resultó en la multiplicación de las inundaciones en las llanuras: entre 1955 y 1975, el costo anual de los daños causados por ellas se multiplicó por catorce ${ }^{28}$.

Ha provocado el empobrecimiento de los ecosistemas y la apertura en determinadas regiones de una duradera "crisis de tijera" entre la disminución de los recursos naturales y la explosión demográfica. El crecimiento numérico de los grupos étnicos que practican la agricultura migratoria de roza y quema en las selvas tropicales en casi un tercio de su área en 1975 ha llevado al desequilibrio general de esta agricultura: acortar en medio siglo la duración promedio del barbecho actualmente. Por debajo de los quince años, alteración del suelo, desmonte de bosques en laderas, erosión irreversible del suelo, etc. Sobre todo, la implementación de políticas deliberadas que combinan la exportación a gran escala de madera por parte de las empresas madereras, el desarrollo de la ganadería extensiva y la "transmigración" de campesinos sin tierra introducidos en el siglo XX y especialmente después de la década de 1950. Las selvas tropicales de la zona intertropical en un ciclo alucinante de limpieza continua. En el Tercer Mundo, fue también en el siglo $X X$ cuando las tensiones ambientales del viejo tipo alcanzaron su clímax. La deforestación, la sobreexplotación de las tierras cultivadas y el pastoreo excesivo continúan provocando la desertificación, como lo han hecho durante milenios. En 1984 se estimó que afectaba a un tercio de la superficie de los continentes y a más de 850 millones de personas, es decir, a más del $20 \%$ de la población mundial ${ }^{29}$.

Desde 1930, el desierto de Thar ha crecido un promedio de 13.000 hectáreas por año hacia el noreste de la península india. Durante el último medio siglo, en el Sahel la zona entre las isoyetas de 100 y $500 \mathrm{~mm}$ de lluvia, el desierto ha progresado a una velocidad media estimada en $2 \mathrm{~km}$ por año. Brasil ha perdido la mitad de su superficie forestal antes de la colonización europea, y la tasa de devastación fomentada oficialmente en la selva amazónica ha crecido hasta tal punto que podría ser completamente destruida a principios del siglo XXI.

En cuanto a China, tiene sólo del 6 al 13\%, según estimaciones, de su superficie forestal y entre 1949 y 1980 perdió entre una cuarta y una quinta parte de una ya insuficiente superficie boscosa ${ }^{30}$. Durante el mismo período, Sichuan, hoy la más poblada de las provincias chinas con cien millones de habitantes, vio la desaparición de un tercio de sus bosques y las autoridades ven esto como uno de los principales factores explicativos de la magnitud del Yangzi, que se teme que se convierta en un "segundo río amarillo", ya que ahora transporta alrededor de 2.500 millones de toneladas de aluvión de cT por año a una tasa de aumento aún mayor que la del Huanghe. Finalmente, en todos los tiempos, la expansión de la pobreza más de mil millones de personas vive hoy, según el Banco Mundial, en un estado de pobreza absoluta ha sido un factor esencial de vulnerabilidad a los riesgos ecológicos. Hoy “, estos pobres absolutos, escribe.

F. Ramade, viven más o menos permanentemente en un contexto de desastre ... Apenas pueden asentarse en tierras de poco valor, a menudo insalubres: favelas en América del Sur,

\footnotetext{
28 F. Ramade, op. cit., pág. I5.

29 lbíd., P. I3.

30 Claude Henry, “La especificidad de la política ambiental china, Revue française d’Administration publique, julio-septiembre de I985;V. Smil, La mala tierra. Degradación ambiental en China, Nueva York, 1984.
} 
construidas sobre tierra firme. Pendiente por lo tanto sujeta al riesgo de deslizamientos de tierra, barrios marginales de Calcuta, instalados en zonas ribereñas de ríos o en llanuras aluviales, miserables campesinos de Bangladesh, más de diez millones de los cuales viven actualmente en zonas deltaicas cuya altitud no supera los tres metros sobre el nivel del mar lo que los hace vulnerables a cualquier ciclón o maremoto"31.

Con el final del siglo $X X$, es de hecho una crisis ecológica acumulativa, un riesgo importante al que ya se enfrenta la humanidad. La industrialización, al desencadenar un fantástico crecimiento demográfico por la revolución pastoril, los descubrimientos terapéuticos del siglo pasado, el espectacular aumento de la producción agrícola mundial ha creado una distorsión creciente entre la capacidad productiva de la biosfera y sus equilibrios de una parte, y la carga humana sobre el otro. Si la humanidad tardó dos millones de años en llegar a cuatro mil millones de personas en 1975 , solo serán necesarios cuarenta para que la tasa actual de crecimiento demográfico duplique esta cifra y para que la población mundial alcance los ocho mil millones de personas. ¡Esto supondrá que la producción agrícola mundial aumenta durante el mismo período en la misma cantidad que lo ha hecho desde el Neolítico! La capacidad de carga de los ecosistemas ya se ha alcanzado en muchos lugares. La industrialización, en su estado actual, no solo induce procesos de deterioro irreversible de los ecosistemas existentes y resulta incapaz de detener los principales procesos clásicos de degradación ambiental, sino que también, en última instancia, cuestiona la existencia incluso desde la biosfera. A este respecto, parece haberse traspasado un umbral alrededor de 1960. Hasta entonces, siendo la población mundial inferior a los tres mil millones de hombres, la producción de los principales recursos biológicos aumentó en paralelo con la cantidad de seres humanos. A partir de esa fecha, la correlación tendió a revertirse y en varias áreas geográficas la población humana comenzó a crecer más rápido que la oferta de recursos. Si las crisis ecológicas generadas por el desequilibrio de la población / capacidades productivas del medio fueron alguna vez regionales o locales, con la globalización del capitalismo industrial, ya no se puede descartar la perspectiva de una situación ecológica crítica a escala planetaria. Esta situación es tanto más preocupante cuanto que ningún intento socialista de romper definitivamente con el modo dominante de producción y consumo ha tenido éxito.

Considerado desde el ángulo de la ecología histórica, el crecimiento de la civilización industrial se alimentó de una sucesión de rupturas locales y regionales de viejos equilibrios ecológicos. Hoy, el espacio de estas rupturas se ha ampliado para abarcar todo el planeta. Al llevarlos al umbral de una "economía mundial”, el capitalismo industrial, en sus versiones históricas "clásicas" así como en sus diversos avatares "socialistas", ha proyectado a las sociedades humanas en una nueva relación con la naturaleza: la de un "ecología mundial". Este es sin duda el primer fundamento del reciente surgimiento de nuevos movimientos sociales que, más allá de las fronteras, se pueden reconocer en la palabra ecología, una palabra que no ha terminado de recorrer el mundo.

Universidad de París VII.

París, octubre de 1988.

31 F. Ramade, op. cit., pág. 15; Este aspecto social de los problemas ambientales acaba de ser ilustrado, una vez más, por las trágicas consecuencias de las inundaciones en Brasil en febrero de 1988. 


\section{RELACIONES INTERNACIONALES}

Revista académica cuatrimestral de publicación electrónica Grupo de Estudios de Relaciones Internacionales (GERI)

Universidad Autónoma de Madrid, España

https://revistas.uam.es/relacionesinternacionales

ISSN 1699 - 3950

f facebook.com/RelacionesInternacionales

3. twitter.com/RRInternacional 